\title{
Study on the Development Trend of Culture Industry in the Era of "Internet Plus"
}

\author{
Xin Cong1, Tianyi Zheng², Lu Bian¹, Jia Wang1 \\ ${ }^{1}$ Yantai Affiliated Hospital of Binzhou Medical University, Yantai, China \\ ${ }^{2}$ Shandong Provincial Hospital (Group) Ludong Hospital, Yantai, China \\ Email: authorsupervip@163.com
}

How to cite this paper: Cong, X., Zheng, T.Y., Bian, L. and Wang, J. (2019) Study on the Development Trend of Culture Industry in the Era of "Internet Plus". Journal of Service Science and Management, 12, 909-915. https://doi.org/10.4236/jssm.2019.127062

Received: November 21, 2019

Accepted: December 28, 2019

Published: December 31, 2019

Copyright $\odot 2019$ by author(s) and Scientific Research Publishing Inc. This work is licensed under the Creative Commons Attribution-NonCommercial International License (CC BY-NC 4.0). http://creativecommons.org/licenses/by-nc/4.0/

\begin{abstract}
In this new era with new situation, the development trend of culture industry in the context of "Internet Plus" determines the advancement of Chinese culture. Uncertainty about development trend constitutes a barrier for culture industry in the new era. The paper explores the challenges and opportunities facing culture industry in the era of "Internet Plus", discusses the feasibility of these challenges and opportunities, and proposes measures for improvement and future development. The paper aims to offer valuable insights for current study of development trend of culture industry in the era of "Internet Plus".
\end{abstract}

\section{Keywords}

Internet Plus, Culture Industry, Development Trend

\section{Introduction}

With the profound impact of the Internet on all aspects of life, the development of cultural industry is also inseparable from the background of the Internet. "Internet plus" represents a new economic form. It refers to the combination of the Internet and traditional industries based on Internet information technology to complete economic transformation and upgrading by optimizing production factors, updating business systems, and reconstructing business models [1]. The paper explores the challenges and opportunities facing culture industry in the context of "Internet Plus", discusses the feasibility of these challenges and opportunities, and proposes measures for improvement and future development.

\section{Features of Culture Industry in the New Era}

Improvement of market entities. Development of culture industry relies on the sound development of market entities. Market entities of new era's culture in- 
dustry have already completed construction and standardization process by following the guiding principles of market-orientation, vitality enhancement and higher significance level [2].

Further optimization of structure of culture industry. In recent years, China has made great efforts to drive the development of culture industry through research projects and social sciences projects implemented by key universities. New cultural contents which are more influential are added to the mainstream culture. In addition to traditional culture, culture industry in the new era also introduces popular elements and thereby winning wide recognition. The new cultural contents are even introduced to other countries creating a "China craze" worldwide.

Cultural innovative ability further strengthened. To support development of culture industry, governments at all levels have taken steps to encourage cultural innovation in areas of funds and technology. By creating smart and user-friendly integrated production line featuring "production-learning-research", cultural innovation has been greatly promoted leading to progress in all-round development-oriented education, cultivation of culture industry related talent and more technological content [3].

Cultural products consumption increased. In addition to pursuing a better material life, people also want a more colorful spiritual life. As a result, they are willing to pay for cultural products they like leading to development of cultural industry and increase in cultural products consumption. According to the 2017 today art museum annual report, the museum's revenue last year was $37,876,900$ yuan, of which tickets accounted for 25 percent. It's worth noting that ticket revenue only accounted for 2 percent of its total revenue in 2016 [4].

Cultural services exports increased. As China is playing a bigger role in the world, a group of brands which feature better brand recognition, export-orientation and internationalization. Currently, people around the world have more opportunities to be exposed to Chinese faces, a fact that results in increase in cultural services exports and narrower culture trade deficit [5]. In 2018, China's exports of cultural services reached $\$ 7.29$ billion, up 18.2 percent year on year. Among them, the total exports of cultural and entertainment services, royalties for research and development achievements such as copyright and royalties for audio-visual and related products, which are at the core of the export of cultural services, reached 1.87 billion us dollars, up $21.4 \%$ year on year [6].

\section{Challenges and Opportunities Facing Culture Industry in the Era of "Internet Plus"}

In the context of "Internet Plus", culture industry faces both challenges and opportunities. The analysis of the development trend of culture industry is as follows:

\subsection{Opportunities Facing Culture Industry in the Era of "Internet PLUS"}

China's stronger support for culture industry. The Chinese government has 
taken various steps to support the development of culture industry in terms of policy, materials and funds. Funds are allocated to national key social sciences projects. Social capital and corporate operation model are introduced to such fields as culture, sports, art, film, music, dance and photography, driving the development of culture industry [7].

More demands from culture industry. With higher material living standards, consumption and needs have also been increased regarding culture industry. Consumption within culture industry can promote the development of the industry. At the same time, the Internet technology improves interaction and consumers' experience allowing the fine traditional culture of China to exhibit its charm and vitality.

Rapid development of new media technologies. In the era of "Internet Plus", both hardware and software of media technologies are improved. As a result, creation of cultural products becomes more diversified and elaborate and recipients have a stronger sense of involvement, which contributes to the preservation, dissemination, refinement and production of cultural products.

Boom of We Media. The rise of Internet and mobile phone drives the boom of We Media, as testified by the emergence of numerous platforms such as blog, Weibo and Wechat. A large number of "Internet celebrities" have appeared gaining fame or fortune. The boom of We Media is undeniably the new opportunity presented by the new era.

\subsection{Challenges Facing Culture Industry in the Era of "Internet Plus"}

A refinement process has created a rich and profound Chinese culture. However, due to its outdated forms, it's not easily accepted by the youth. Challenges facing culture industry include:

Insufficiency of capable management team. Within today's culture industry, there is an insufficiency of professionals who have acquired adequate knowledge about culture management. Culture management teams do not know how to develop overall plan for future development. Only a small number of teams are capable of management and operation. Due to lack of competitiveness, most teams cannot effectively deal with risks increasing uncertainty in the industry.

Weak awareness of copyright protection. Compared with the mature copyright markets of other countries, China has not created a comprehensive system of laws and regulations on copyright protection for culture industry [8]. Culture structural reform has not been completed damping creation enthusiasm of copyright owners.

Underinvestment in culture industry. Although different sectors have provided support for the development of culture industry, they seldom provide continuous support preventing sustainable development and rapid enhancement of the scale and strength of the industry. There's large population and wide area in China, cultural industry sinking needs considerable strength. 


\section{Development Trend of Culture Industry in the Era of "Internet Plus"}

Culture dissemination power of a country exerts a direct influence on the cultural sharing level of its people and the economic outlook of culture industry. Technology is a key driver of cultural development and the innovation goals of culture creators.

\subsection{New Blood for Culture Industry Development}

Development of culture industry relies both on mature core force and new blood. Therefore, those who still receive compulsory education should be expected to develop their cultural literacy. Relevant projects should be conducted at research institutes and institutions of higher learning. To help new blood of culture industry grow up, cultural workers who have promoted the development of culture industry through independent innovation efforts should be offered policy-based support and copyright protection. Those who have disturbed market order of culture industry should receive supervision and punishment [9].

\subsection{Leveraging Information Platform}

In today's world, no one can accomplish anything without "Internet Plus." At this moment, the key task facing culture industry is creating culture contents and forms which feature high-speed, efficiency, wide coverage interaction and entertainment-based education. To achieve this goal, technology information platform must be leverage. By integrating cultural information from different fields and backgrounds, more diverse cultural forms are to be created by using hi-tech information technologies.

\subsection{Wide Application of Intelligent Informatization}

The wide use of mobile terminals such as mobile phone has caused the boom of various forms of We Media. Currently, there are 724 million mobile phone users and the number is expected to grow [10]. Due to the development gap between Eastern China and Western China, more efforts should be made for the popularization of value-added service such as intelligent informatization so as to bring tangible benefits to the general public.

\subsection{Multi-Form Development of Culture Industry}

In the era of "Internet Plus", the gap between culture industry and concrete cultural products is eliminated, as well as the distance between producers and recipients. Combining various factors from culture industry such as software, hardware, creative ideas, resources and capital, industries connected with culture industry are integrated into a cooperation mechanism. Through continuous extension and growth, a development pattern featuring multi-aspect and multi-form is created for the culture industry, a move in line with the current general situation. 


\section{Development Goals and Strategies for Culture Industry}

On the basis of the foregoing analysis, some goals and strategies for culture industry in the era of "Internet Plus" are proposed.

\subsection{One Goal}

One goal: Direct the development of culture industry in the new era via high standards and scientific modes; build "I + CI mode" into a unique and trustworthy brand of culture.

\subsection{Three Transformations}

Transformation of development mode. Develop socialist culture with Chinese characteristics for a country with brand power via information platform; enhance cultural confidence and integrate quintessence of Chinese culture with development trend of the new era; achieve deeper and wider development through high-tech and intelligent information platforms.

Transformation of management philosophy. Improve management philosophy for economic management and talent management while developing content-oriented culture industry so as to create a scientific management mode; attract talent from various fields such as management, finance and scientific research; more efforts to be made to attract high-level overseas talent from such fields as cultural creativity, R\&D and management so as to build an effective talent pool for culture industry development in China.

Transformation of service philosophy. Traditional service philosophy of culture industry is not clear about its goal. Culture creators focus too much on the quality of cultural products and ignore the emotional experience of recipients. In addition to quality of cultural products, culture industry should also focus on the humanistic value of cultural products and increase recipients' acceptance rate and repurchasing rate, developing a comprehensive system of humanistic service philosophies.

\subsection{Four Improvements}

Improvement of creation efficiency of cultural workers. To improve creation efficiency of cultural workers, a favorable work environment is a necessity. An intelligent and high-speed work platform should be provided to stimulate their creativity. New forms should be created for showcasing achievements of culture industry. A wider range of cultural products should be developed. More convenient and efficient transmission and exhibition platforms should be utilized.

Improvement of quality of cultural products. Improvement of quality of cultural products is a guarantee of the sustainable development of culture industry. The cultural literacy and humanistic quality of cultural workers must be increased. Cultural programs of significance are to be created in line with the policies of the central government. Programs and entertainers who have negative influence on society should be banned so as to create a healthy cultural environ- 
ment.

Improvement of salary of cultural workers. As people are the key element of development of culture industry, the salary of cultural workers determines the stability and sustainability of the industry. Therefore, increasing salary of cultural workers is of critical importance. Cultural workers do not mean ultra-high income actors or "flow stars". In this paper, cultural workers are defined in a narrow sense as salarymen engaged in work related to cultural activities. Different from those shallow entertainers, serious cultural workers should earn a good salary to match their contributions to culture dissemination and research. Those star entertainers who are paid a lot of money through "dual contract" should be severely punished so as to facilitate a healthy development of culture industry.

Improvement of hardware of culture industry. Improvement of hardware facilities is a precondition for development of culture industry. Acceleration of informatization, $S \& \mathrm{~T}$ research and application within the culture industry is one of the key steps to be taken. Integrating advanced technologies of different fields and applying them to culture development is a feasible option of future development of the industry.

\section{Conclusion}

By focusing on the development of culture industry in the era of "Internet Plus", the paper analyzes the current development of culture industry. By analyzing the development of traditional culture industry, the paper explores the development trend of culture industry in the era of "Internet Plus". After analyzing the challenges and opportunities facing culture industry, the paper proposes goals and strategies for culture industry development in the new era, namely, one goal, three transformations and four improvements, which are of important significance for the future development of culture industry in the era of "Internet Plus". It is conducive to increase the confidence of practitioners, to accelerating the pace of cultural industry development, to enriching people's spiritual and cultural life, to the development of the national one hundred plan.

\section{Funding}

Project: Shandong Province Art Science key topic, the Internet + The Times culture industry development new direction research (QN201906126).

\section{Conflicts of Interest}

The authors declare no conflicts of interest regarding the publication of this paper.

\section{References}

[1] Ma, S.Y. (2018) The Development of Cultural Industry in the Internet Era Is in a New Direction. World of Management, No. 2, 180-181.

[2] Xie, X.F. and Zang, Z.P. (2018) A Study of Space Distribution and Clustering 
Mechanism of Listed Companies in Culture Industry in the "Internet Plus" Era. Southeast Academic Research, No. 2.

[3] Huang, X., Wang, B. and Wu, C. (2017) Research on Mode of Safety Culture Development in Context of "Internet+". China Safety Science Journal, No. 5, 13-18.

[4] Foreign Media: How Can Internet Bridge Chinese Literary Landmarks Become "Fashionable"? (2018) http://mini.eastday.com/a/180226172525636-3.html

[5] Zhang, S.B., Xu, X.Y. and Ma, S.H. (2014) Introduction to the Global Cultural Industries. Peking University Press, Beijing.

[6] Ministry of Commerce of the People's Republic of China. (2019) Report on the Development of China's International Cultural Trade, 2019-06-03.

[7] Jiang, N.Y. (2017) Thinking about the Development Path of Cultural Industry in Context of "Internet+". Theoretical Exploration, No. 12, 32-34.

[8] Chen, B.F. and Yang, H. (2017) Research on Business Mode of Culture Industry on the Background of "Internet+". Journal of Hunan University of Commerce, No. 24, 23-32.

[9] Ning, S.Y. (2016) Thinking Based on the "Internet+" Cultural Industry Management. China Newspaper Industry, No. 10, 78.

[10] Li, M.Z. and Zhu, T.T. (2016) Research on the Development of Chinese Cultural Soft Power in the "Internet Plus" Era. The Yangtze River BBS, No. 5, 67-71. 